\title{
Surgical Extrusion of a Complete Crown Fractured Tooth: A Case Report
}

\author{
Senem Yiğit Özer ${ }^{1}$, İbrahim Uysal' ${ }^{2}$ Emrullah Bahşi ${ }^{3}$ \\ ${ }^{1}$ Assistant Professor, Dicle University, Faculty of Dentistry, Department of Endodontics, Diyarbakır, TURKEY \\ ${ }^{2}$ Research Assistant, Dicle University, Faculty of Dentistry, Department of Endodontics, Diyarbakır, TURKEY \\ ${ }^{3}$ Assistant Professor, Dicle University, Faculty of Dentistry, Department of Operative Dentistry, Diyarbakır, TURKEY
}

\section{Key Words}

Dental trauma, complete crown fracture, root extrusion, splinting.

\section{Correspondence: \\ Senem YİĞİT ÖZER \\ Dicle University, \\ Faculty of Dentistry, Department of Endodontics, 21280, Diyarbakir, TURKEY. e-mail: senemygt@hotmail.com}

\begin{abstract}
Complete crown fracture is a dental injury affecting enamel, dentin, and pulp and unfortunately crown is lost usually due to loss of tooth structure. Root-crown lengthening can be performed if an acceptable root-crown ratio is preserved for the retention of root. This paper presents a case report of a mandibular canine incisor tooth having complete crown fracture. Root-crown lengthening is performed by surgical extrusion of the root coronally, splintted using a semi-rigid splint and prognosis was successful after one year later. Treatment of complete crown fracture by surgical extrusion and splintting may be a good alternative for general practitioners since it is an easy and short time requiring technique necessiating less equipments.
\end{abstract}

(Int Dent Res 2011;2:70-74)

\section{Introduction}

Dental and periradicular structures can be damaged through traumatic injuries, and the management of these injuries usually involves multidisciplinary treatment approaches. Generally, diagnostic and therapeutic interventions following dental injuries are not part of routine practice at a dental office, and the clinician may be unsure as to which treatment modality should be used for dentoalveolar trauma $(1,2)$.

Complete crown fracture (CCF) is a type of dental injury involving enamel, dentine, and pulp that occurs in $0.9-18 \%$ of all dental injuries (3). Treatment of CCF may necessitate the application of various treatment techniques, depending on the severity of the trauma. If pulp is vital, treatment options comprising pulp capping, partial pulpotomy, or pulpectomy are preferred $(4,5)$. However, the pulp is usually affected dramatically by trauma. If the pulp becomes necrotic, a routine root canal treatment will be the treatment of choice. If the crown is totally destroyed, surgical or orthodontic extrusion of the root for future restorations and modified restorative techniques may be an alternative treatment approach.

It is advisable to splint after repositioning a tooth that has been subjected to trauma to maintain its original position and prevent displacement and further injury to the periodontal ligament during the healing stage (6-8). Several types of splints are used in clinical practice in rigid and semi-rigid forms (9). Rigid splints provide immobilization and are usually used over the long-term for jawbone fractures to prevent the physiological movement of the teeth (7). On the other hand, semi-rigid splints are somewhat flexible, allowing physiological tooth movement and are used in the short term $(10,11)$ in avulsion, luxation, or fracture cases. Long-term rigid splinting, between 2 and 6 weeks, is believed to increase the severity and frequency of the occurrence of external root resorption (11-14), whereas, in contrast, semi-rigid splints have been reported to perform better in preventing root resorption by accelerating the rate of periodontal reorganization and reattachment $(11,12,15)$. 
The aim of the present case report is to describe the clinical management of a mandibular canine incisor tooth presenting complete crown fracture and to discuss the treatment decisions and outcomes.

\section{Case Report}

A 19-year-old male was referred to the Department of Operative Dentistry and Endodontics, Faculty of Dentistry, University of Dicle (Diyarbakir, Turkey) for the treatment of the right mandibular canine incisor tooth (Fig. 1A). He reported being involved in a car accident in which he had been knocked into another passenger 3 days earlier. He also said that the same tooth had undergone root canal treatment due to spontaneous pain 2 weeks previously, and that treatment had not yet been completed. Clinical examination revealed a CCF below the cemento-enamel junction (Fig. 1B). No bleeding was observed around the gingiva, and the tooth was asymptomatic. Periapical radiographs demonstrated a long root of the canine incisor with no fracture and a slight radiolucency in the apical portion (Fig. 1C). A temporary filling had been placed in the access cavity related to the former endodontic treatment. A careful examination was done to assess possible injuries by visual inspection and palpation, and teeth on both sides were evaluated for mobility. The mandibular right lateral incisor and mandibular first premolar were intact, and their mobilities were within normal limits. Considering the long root formation of the canine incisor tooth, surgical extrusion and stabilization of the tooth via a semi-rigid splint was planned for crown lenghtening.

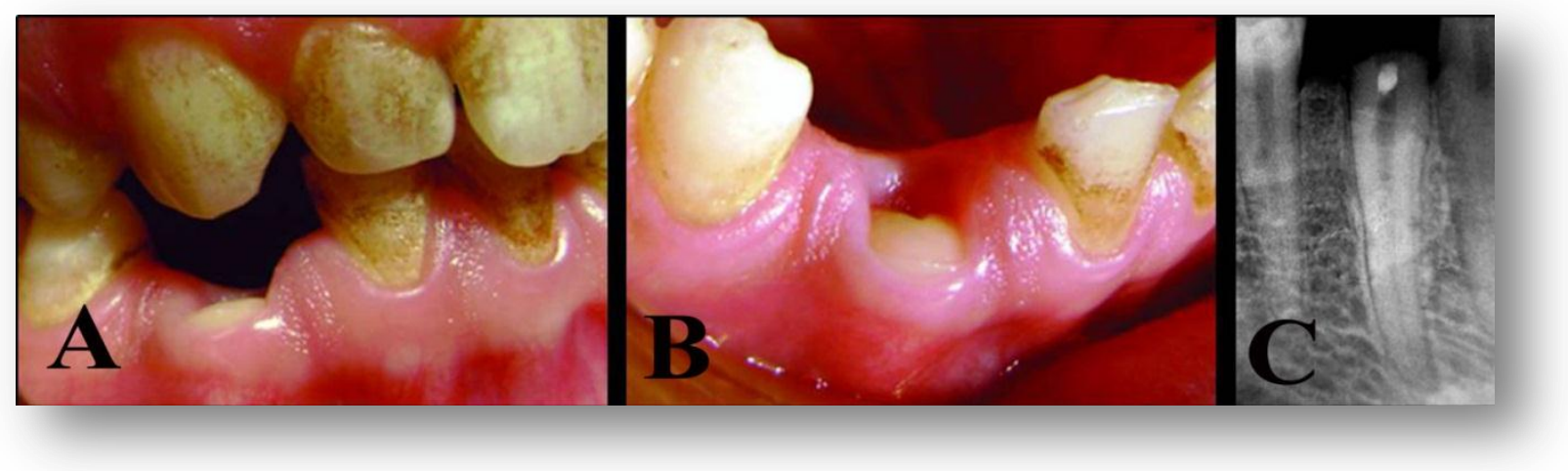

Figure 1. (A) Crown-root fracture of right mandibular canine tooth. (B) The crown is totally fractured 2-3 mm below the cemento-enamel junction. (C) Radiographic appearance of mandibular canine tooth.

The access cavity was redesigned, the working length was established, and a root canal was instrumented with the ProTaper rotary system (Dentsply/Maillefer, Tulsa, OK, USA) to size F3. Calcium hydroxide was used as an intracanal medicament, and the access cavity was restored with a resin-reinforced glass ionomer cement (GC
Fuji Plus, GC Inc., Alsip, IL, USA). To avulse the root, adequate anesthesia was achieved with $2 \%$ procaine-hydrochloride (Isocain; ASID $\mathrm{GmbH}$, Holzolling, Germany), gingival decollation was gently performed, and the root was extruded 3-4 mm coronally.

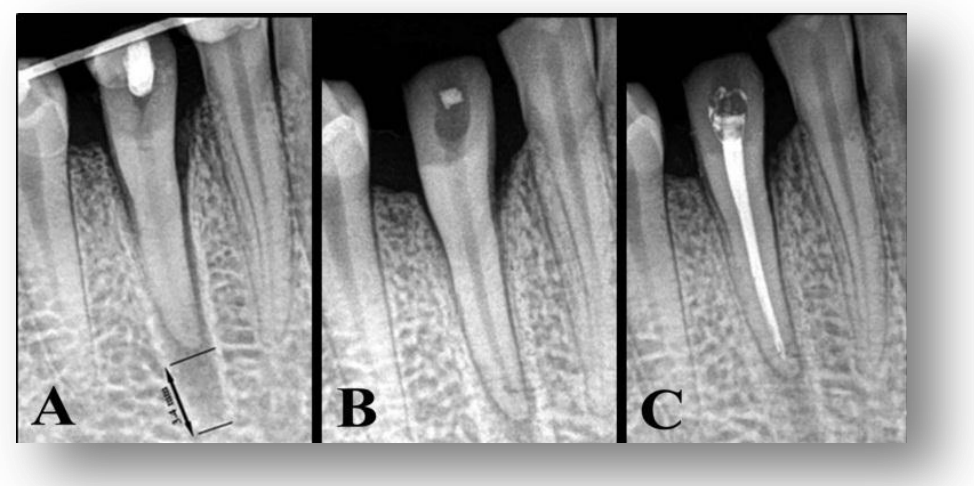

Figure 2. (A) Radiograph after the extrusion and splinting procedures. (B) The wire-composite splint was removed 2 weeks later. (C) Radiograph after root canal filling. 
After, repositioning bleeding was controlled, and periodontal paste (Peripac; Dentsply) was placed around the gingival margins for protection. In the same visit, a wire-composite splint was prepared; $0.016 \times 0.016$ inch nickel-titanium orthodontic wire was cut, isolation was achieved using cotton rolls, and adhesion areas for the splint were prepared with single-step bonding (Prompt LPomp; 3MESPE, St. Paul, MN, USA) on the lingual and occlusal surfaces of the repositioned tooth and neighboring teeth. A thin layer of flowable composite resin (Filtek Flow; 3MESPE) was applied on the enamel surfaces to position the wire. The wire was held in place using a hemostat and one end of the wire was attached on the first abutment tooth with composite resin (Filtek Z 250; 3MESPE). After polymerization, the other end of the wire was attached to the remaining abutment tooth, and the same procedure was repeated. Care was taken to avoid dislodging the repositioned tooth. After the abutment teeth had been splinted, the position of the repositioned tooth was checked to ensure proper alignment, and it was attached to the wire using the composite resin in the same manner. Occlusion was checked, and premature contacts were eliminated (Fig. 2A). The protruding wire ends were trimmed, and composite bulks were smoothened and polished for the patient's comfort and hygiene, taking care not to deform the wire. Stabilization of the splint was clinically and radiographically evaluated on the fifth day, and at the first and second (Fig. 2B) weeks after the operation. Two weeks after the splinting procedure, the mobility of the canine incisor was clinically acceptable, and the wire-composite splint was removed in the same session. Root canal filling was than performed using special-tapered guttapercha points (ProTaper Universal Gutta Percha, Dentsply) and a calcium hydroxide-based root canal sealer (Sealapex; Kerr Co., Romulus, MI, USA), and treatment was complete (Fig. 2C).

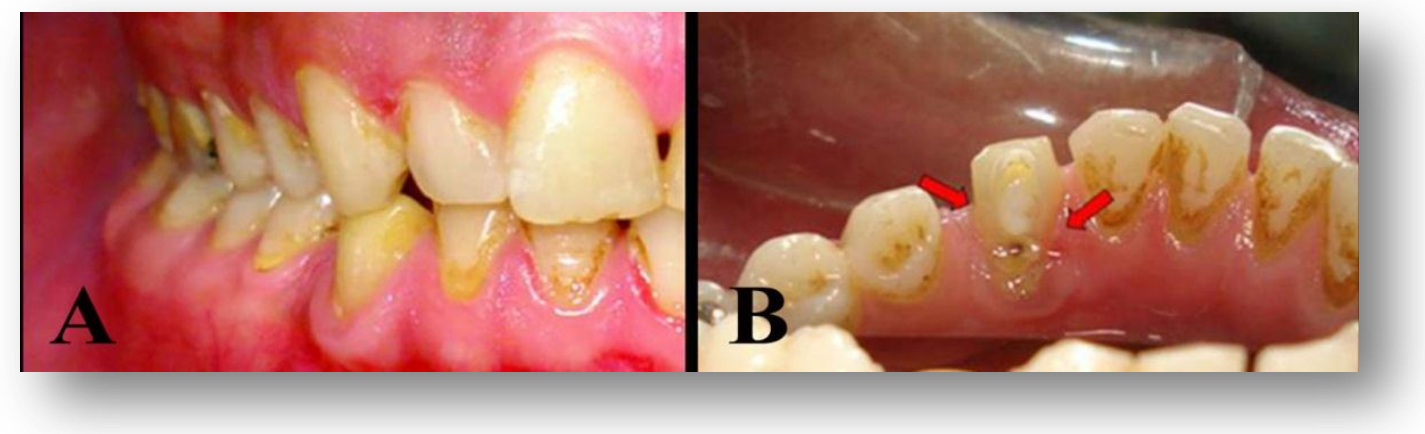

Figure 3. (A) Mandibular canine incisor is in tight occlusion with its antogonist. The tooth is intact buccally. (B) Note the oblique tooth fracture lingually.

A full ceramic crown was planned to complete the restoration, but the patient was required to join the army, and this treatment was not completed. Twelve months later, he was recalled, and an intraoral investigation was done. The mandibular canine was intact buccally, with an oblique cusp fracture lingually (Fig. 3A, 3B), mobility was within normal limits, bone formation was complete apically, the lamina dura was visible radiographically (Fig. $4 \mathrm{~A}$ ), and the tooth was in tight occlusion with its antagonist. Periodontal probing showed good health, and the tooth was restored with a full ceramic crown (Fig. 4B).

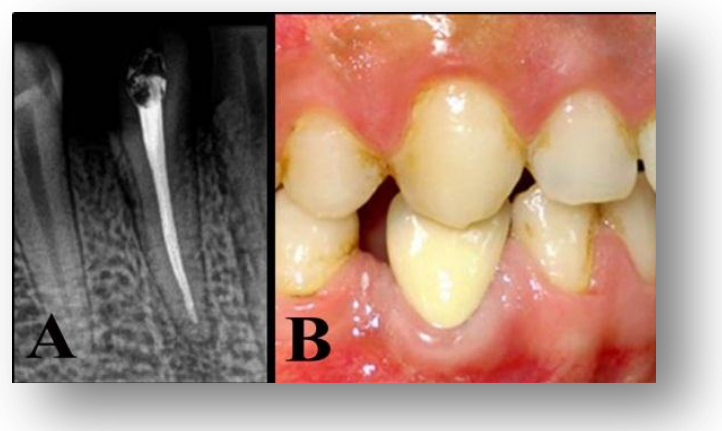

Figure 4. (A) One year follow-up radiograph. (B) Final restoration of the mandibular canine incisor. 


\section{Discussion}

Surgical or orthodontic extrusion to save cervically root-fractured teeth has been recommended previously $(16,17)$. Although orthodontic treatment render a more biological way of extruding the tooth, surgical extrusion, a one-step procedure, is simpler and less time-consuming than orthodontic extrusion, in which the patient's cooperation is accepted as a critical factor (16). Clinical studies have reported successful treatment outcomes using surgical extrusion (16-19). Çalışkan $(18,19)$ demonstrated that this treatment modality was successful because surgical extrusion prognostically could be compared with extrusive luxation of teeth which has favorable prognosis with a low incidence of root resorption. Because the root do not leave the alveolar socket, the potential deleterious effect of drying the periodontal cells is eliminated. Since the viability of the cementoblasts is a major factor for the healing of the socket and formation of periodontal membrane (20) surgical extrusion have such advantages on healing. However, during surgical extrusion, treatment outcome may be negatively affected due to the damage by instruments, and the difficulty of surgery (21).

Splinting has become a customary part of the treatment of replanted avulsed teeth (6) and splints have been suggested to promote periodontal repair $(6,7)$. A semi-rigid, functional splint is firm enough to retain the tooth in the socket, allowing periodontal stimulation during function $(10,11,22)$, and is indicated for luxation and avulsion injuries by the International Association for Dental Trauma (IADT)(1) and the American Association of Endodontists (AAE) (2). The duration of splinting is recommended at 7-14 days by the AAE and up to 2 weeks by the IADT. Physiological micro movement has been reported to maintain blood circulation in the healing ligament (15) and to stimulate revascularization, providing periodontal reattachment and reorganization. In contrast, with immobilization by rigid splinting, healing of the periodontal tissues is prevented, resulting in reduced collagen mass (23).

Cengiz et al. (24), in an in vitro study, evaluated the effect of splint type on stresses occurring around traumatized teeth with three different semi-rigid splints and advised the use of orthodontic wire-composite splint to create the lowest stress around traumatized teeth. Thus, a wire-composite functional splint was used in the case.

Teeth replanted with preservation of periodontal ligament vitality, cementum integrity (25) and minor bacterial contamination $(26,27)$ have been reported to have good prognosis with a high survival rate. In the replantation of avulsed teeth, maintenance of the vital periodontal ligament on the root surface is extremely important for fiber reattachement (26).

A well-planned and limited avulsion in the present case definitely preserved periodontal ligament vitality, and the treatment outcome was success, with functional healing. Indicators of functional healing have been defined as no root resorption (27), mobility within normal limits (11), intact lamina dura on radiographs (27), and no radiographic sign of root resorption (11). All of these factors were true in the present case.

It should be kept in mind that cement on the root surface is softer than enamel (28). Also, deminerilization on root surfaces develops twice as fast as that on enamel because the mineral content of the root is poorer than the enamel (29). If intentional avulsion of a root is planned in a case of CCF, a prosthetic restoration should immediately be placed on the final tooth structure to prevent demineralization and other possible trauma. Although the tooth structure was intact buccally in this case, a minor oblique fracture was present, indicating undesirable tooth structural loss due to the delayed final restoration.

\section{Acknowledgments}

The authors deny any conflicts of interest related to this study.

\section{References}

1. http://www.iadt-dentaltrauma.org/Trauma/dental trauma.htm

2. $\bar{h}$ ttp://www.aae.org/dentalpro/guidelines.htm

3. de Blanco LP. Treatment of crown fractures with pulp exposure. Oral Surg Oral Med Oral Pathol Oral Radiol Endod 1996;82:564-8.

4. Cvek M. Partial pulpotomy in crown-fracture incisors: results 3 to 15 years after treatment. Acta Stomatol Croa 1993;27:167-73.

5. Fuks $A B$, Chosack SGA. Long-term follow-up of traumatized incisors treated by partial pulpotomy. Pediatr Dent 1993;15: 334-6.

6. Andreasen JO, Andreasen FM. Textbook and color atlas of traumatic injuries to the teeth, 3rd edn. Mosby: Munksgaard; 1994.

7. Kehoe JC. Splinting and replantation after traumatic avulsion. JADA 1986;112:224-30.

8. American Association of Endodontists. An annotated glossary of terms used in endodontics, 7th edn. Chicago: American Association of Endodontists; 2003. 
9. Mandel $U$, Viidik A. Effect of splinting on the mechanical and histological properties of the healing periodontal ligament after experimental extrusive luxation in the monkey. Arch Oral Biol 1989;34:209-17.

10. Ram D, Cohenca N. Therapeutic protocols for avulsed permanent teeth: review and clinical update. Pediatr Dent 2004;26:251-5.

11. Andreasen JO. The effect of splinting upon periodontal healing after replantation of permanent incisors in monkeys. Acta Odont Scand 1975;33:313-23.

12. Kristerson L, Andreasen JO. The effect of splinting upon periodontal and pulpal healing after autotransplantation of mature and immature permanent incisors in monkeys. Int J Oral Surg 1983;12:239-49.

13. Barbakow FH, Cleaton-Jones PE. Experimental replantation of root canal-filled and untreated teeth in the Vervet monkey. J Endod 1977;3:8993.

14. Morley RS, Malloy RB, Hurst RVV, James R. Analysis of functional splinting upon autologously reimplanted teeth. IADR Abstracts 1978;17:593.

15. Yasuda T, Kinoshita M, Abe M, Shibayama Y. Infavorable effect of knee mobilization on Achilles tendon healing in rabbits. Acta Orthop Scand 2000;71:69-73.

16. Kahnberg K-E. Surgical extrusion of rootfractured teeth-a follow-up study of two surgical methods. Endod Dent Traumatol 1988;4:85-9.

17. Saad AY, Abdellatief E-SM Surgical repositioning of unerupted anterior teeth. J Endod 1996;22:376-9.

18. Çalışkan MK. Surgical extrusion of a completely intruded permanent incisor. J Endod 1998;24:381-4.

19. Çalışkan MK. Surgical extrusion of a cervically root-fractured tooth after apexification treatment. J Endod 1999;25:509-13.

20. Hammarström L, Blomöf L, Lindskog S. Dynamics of dentoalveolar ankylosis and associated root resorption. Endod Dent Traumatol 1989;5:16375.

21. Mamber EK. Treatment of intruded permanent incisors: a multidisciplinary approach. Endod Dent Traumatol 1994;10:98-104.

22. Bill Kahler, Geoffrey S Heithersay. An evidencebased appraisal of splinting luxated, avulsed and root-fractured teeth. Dent Traumatol 2008;24:210

23. Amiel D, von Schroeder $H$, Akeson WH. The response of ligaments to stress deprivation and stress enhancement. In: Daniel DM, Akeson WH, O'Connor JJ, editors. Knee ligaments: structure, function, injury and repair, Vol. 16. New York: Raven Press; 1990. p. 329-36.

24. Cengiz SB, Atac AS, Cehreli ZC. Biomechanical effects of splint types on traumatized tooth: a photoelastic stress analysis. Dent Traumatol 2006;22:133-138

25. Wallace JA, Vergona K. Epithelial rests function in replantation: is splinting necessary in replantation? Oral Surg Oral Med Oral Pathol 1990;70:644-9.
26. Harmmarstrom L. Enamel matrix, cementum development and regeneration. J Clin Periodontol 1997;24:658-68.

27. Trope M, Moshonov J, Nissan R, Buxt P, Yesilsoy C. Short vs. long-term calcium hydroxide treatment of established inflammatory root resorption in replanted dog teeth. Endod Dent Traumatol 1995;11:124-8.

28. Lynch E. Relationship between clinical criteria and microflora of primary root caries. Early Detection of Dental Caries. Cincinnati, OH; Sidney Printing Works. 1996;195-242.

29. Featherstone JDB. Flouride, remineralization and root caries. Am J Dent 1994;7:271-4 